\title{
Evaluating the Student Activity Meter: two Case Studies
}

\author{
Sten Govaerts, Katrien Verbert, and Erik Duval \\ Katholieke Universiteit Leuven \\ Dept. Computer Science \\ Celestijnenlaan 200A, 3001 Heverlee, Belgium \\ \{sten.govaerts, katrien.verbert, erik.duval\} @cs.kuleuven.be \\ http://hci.cs.kuleuven.be/
}

\begin{abstract}
In the Technology Enhanced Learning (TEL) domain, visualizations are attracting increased interest. In this paper, we present the Student Activity Meter that visualizes learner activities within online learning environments for learners and teachers to help increase awareness and to support self-reflection. We present evaluation results of two case studies with teachers, learning analytics students and experts. Results from teachers show that the visualizations can assist in creating awareness, understanding of student resource use and student time spending behavior. SAM's three visualizations were perceived as equally useful, but for different tasks. The evaluation participants also identified new metrics to extend our current set and prioritized new visualization ideas.
\end{abstract}

Keywords: Visualization, Self-reflection, Awareness, Case Study

\section{Introduction}

With co-located learning in a physical classroom, learners interact directly with teachers and learners. In a digital environment, learners often struggle to position their work and to assess if it matches the teacher's expectation [3]. Teachers experience similar problems online, e.g. tracking progress and detecting learners in need. In recent years, research on learning analytics $[3,1]$ evolved and describes measurement, tracking, analysis and visualization of data about learners. Capturing user activities is often a basis to analyze student behavior [2] and can be modeled with e.g. CAM [17] and UICO [11].

Visual analysis is a key enabler to gain insights into the learning process and provides a basis to support self-reflection, awareness and collaboration among learners or teachers [15]. Studies have shown that visualizations enable understanding [16] and discovery of patterns [2]. Our tool, SAM (Student Activity Meter), visualizes time spent on learning activities and resource use in online learning environments. An earlier study of SAM [5] with students evaluated its usability. This paper presents two case studies of SAM in real teaching and learning scenarios. We identify requirements and preferences of users and evaluate how and for which purposes they would use SAM. The first case study evaluates the usefulness for teachers. A second case study assessed the perceived usefulness of participants of a learning analytics course. Their visualization expertise provides useful feedback and the evaluation results will be used to improve SAM.

The paper is organized as follows: we first present related research, then the objectives and the design of SAM. Section 4 describes two case studies, the evaluation methodologies and results. Conclusions and future work are outlined in Section 5. 


\section{Related Work}

Soller et al. [15] identify categories of visualizations that support self-reflection, awareness and collaboration among learners. A first category includes systems that improve awareness of resource use, e.g. along a time-line. The second class aggregates data into high-level indicators, e.g. participation rates based on word counts, and relates this to a model. SAM visualizes and allows analysis of activities and resource use over time. Hence, it situates itself in the first, because it shows student activities over time, and partly in the second category through simple statistics on time spent and document use.

Several other systems visualize learner activities to support awareness and selfreflection. CAMera [12] is an application that visualizes user activities and simple metrics of events, e.g. mouse clicks. The system relies on the CAM schema [17] that captures user interactions with tools and resources. SAM also uses CAM data, but focuses on higher-level indicators, e.g. the time spent on learning activities. Moodog [18], a Moodle plug-in, visualizes activity logs to enable learners to compare their progress and provide teachers with insights. The statistics per user or resource are presented in a table of numbers combined with bars for visual comparison. We use similar metrics as Moodog (e.g. total views and total time), but with more advanced visualizations.

Other applications visualize communication and collaboration between learners. The Participation Tool [7] uses the communication between learners to increase motivation. The Social Networks Adapting Pedagogical Practice tool, SNAPP [4], visualizes learner social networks and their interactions, in order to understand the participation and performance. Larusson et al. [10] visualize blogging activity, e.g. conversations.

Although systems mentioned above use visualizations to support awareness, selfreflection and collaboration, only a few studies have been conducted that assess the usefulness of visualizations for teachers and learners in real-life scenarios. In this paper, we present case studies that present first insights into how and why teachers and learners would use visual analysis systems in real-life to increase awareness and self-reflection.

\section{Objectives and Design}

\subsection{Objectives}

SAM can be used by both teachers and learners in personal learning environments (PLE) [6], which are user customizable learning environments that allow creation and mashup of resources and tools. PLEs are often used in self-regulated learning where self-monitoring and self-reflection is important [19].

First, we describe briefly the teacher objectives of SAM, which are important for both case studies of Section 4.1. Then, we discuss learner goals, which are assessed in the learning and knowledge analytics (LAK) course case study (see Section 4.2).

Teacher goals. SAM provides support for the following teacher objectives:

- Awareness for teachers of what and how learners are doing is important to assess learner progress. This is difficult in online and distant courses due to lack of faceto-face communication. SAM provides visual overviews of the time learners spent 


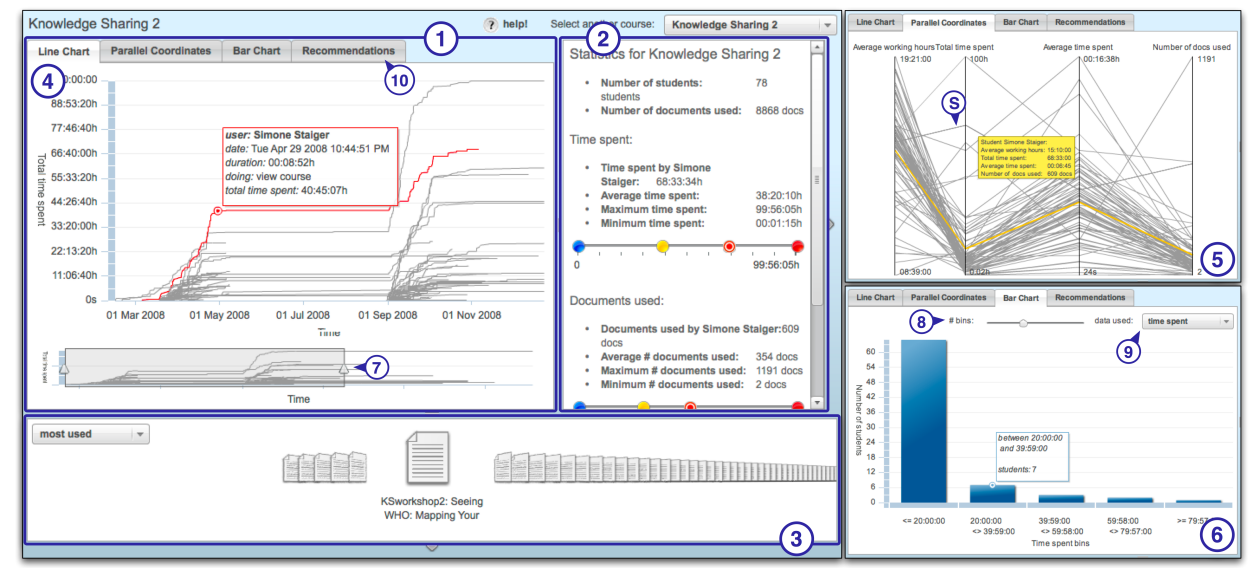

Fig. 1: The user interface with the three different visualizations.

and the resources they use. Both are good indicators for awareness [8]. The visualizations can be used by teachers to find patterns and spot potential problems.

- Time tracking information allows teachers to assess their initial time estimates with the real time spending of students and find the exercises that consume most time.

- The resource usage can show the popular learning materials and enables resource discovery, through a list of most used or most time spent on resources in SAM.

Learner goals. SAM targets the following objectives for learners:

- Self-monitoring can provide self-reflection and awareness. SAM visualizes when, on which resources and how long learners have been working in comparison to their peers. Discovery of averages and trends in the monitoring data is also possible.

- Time tracking can help the learner to understand his time allocation compared to his peers and assist sometimes to report time spending to the teacher.

- Resource recommendation provides related interesting learning material used by their peers. This can be especially useful in self-regulated learning.

\subsection{Visualizations and Design}

Fig. 1 shows the visualizations that SAM provides in teacher mode (see box 1). In learner mode, the user is highlighted in green for fast lookup. Three visualizations were iteratively designed using paper mockups. SAM is a fully implemented web application and is independent of a learning environment. SAM relies on CAM [17] data for interoperability. For both case studies ${ }^{1}$ CAM data was generated from Moodle logs.

\footnotetext{
${ }^{1}$ The tool is available at http://ariadne.cs.kuleuven.be/ monitorwidget-cgiar for the CGIAR case study and at http://ariadne. cs.kuleuven.be/monitorwidget-lak11 for the LAK case study
} 
The statistics of global time spent and document use are shown in box 2 in Fig. 1. Next to the actual numbers, a graphical view is presented with color-coding.

The recommendation pane presents a list of the top most used resources or those on which the most time was spent (box 3). The 'Recommendations' tab (see label 10) contains an animated tag cloud of the recommendations. We opted for a tag cloud, because the information-seeking task is not clearly defined and exploratory [14].

The line chart (vis. 4) shows a line for every student, connecting all the timestamps with the cumulative amount of time spent. The horizontal axis shows the date and the vertical axis the total time spent. The inclination of the line shows the student's effort. A steep line means an intensive working period. A flat line shows inactivity. The selected student (in red) has been working hard from March to May 2008, then idled until September, when he re-started again. For more details, a specific period can be selected the small chart below (see label 7). The chart enables teachers and learners to compare with similar learners and to find out on what activities or resources they spent their time.

Parallel coordinates [13] (vis. 5) are a common way to visualize high dimensional data. The vertical axes represent: the median of the time of day that students work, the total time spent on the course, the average time spent on a resource and the number of resources used. A learner is shown as a polyline where the vertex on the $\mathrm{i}^{\text {th }}$ axis corresponds to the $\mathrm{i}^{\text {th }}$ data point. The yellow line shows a calculated average student for comparison. The selected student, $\mathrm{S}$, works preferably in the afternoon, spends the $2^{\text {nd }}$ most time in total and uses many resources for a bit above average time. This is a more advanced visualization that can provide an overview of the tendencies.

The bar chart (vis. 6) shows the student distribution for the total time spent and the resources used. The bar chart allows grouping of students and provides a visual impression of the distribution. One can drill down in the data by clicking on a specific bar. The slider (see label 8) and the drop-down list (see label 9) at the top right allow to change respectively the number of bins and the metric. The bar chart allows to better understand the distributions, group the learners and to grasp the overall course state.

\section{Case studies and evaluation}

Two case studies are presented: the agroforestry courses of $\mathrm{CGIAR}^{2}$ and the open online course of Learning and Knowledge Analytics (LAK) ${ }^{3}$.

\subsection{The CGIAR case study}

In this case study, we applied the design based research methodology [9]. We presented SAM to teachers to evaluate whether SAM could assist teachers with their teaching tasks and whether the functionalities of SAM would be useful for them.

Evaluation Setup and Demographics Nineteen CGIAR teachers, teaching different agroforestry and science related courses on the same Moodle ${ }^{4}$ system, were contacted.

\footnotetext{
${ }^{2}$ CGIAR - Consultative Group on International Agricultural Research, http: / / cgiar.org

${ }^{3}$ LAK course, http://scope.bccampus.ca/course/view.php?id=365

${ }^{4}$ Moodle, http: //www. moodle.org
} 


\begin{tabular}{|c|c|c|c|c|c|c|c|c|}
\hline & \multicolumn{4}{|c|}{ Issues } & \multicolumn{4}{|c|}{ Addressed by tool } \\
\hline & $\stackrel{0}{\Sigma}$ & 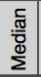 & 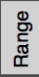 & $\underline{\underline{r}}$ & $\frac{0}{8}$ & 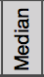 & 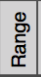 & $\begin{array}{l}\tilde{\pi} \\
\underline{0}\end{array}$ \\
\hline $\begin{array}{l}\text { Provide feedback to the } \\
\text { students }\end{array}$ & 5 & 5 & 3 & 1 & 4 & 3 & 4 & 2 \\
\hline $\begin{array}{l}\text { Being aware of what the } \\
\text { students are doing }\end{array}$ & 4 & 4 & 3 & 1 & 4 & 4 & 2 & 1 \\
\hline $\begin{array}{l}\text { about collaboration } \\
\text { mmunication * }\end{array}$ & 3 & 4 & 3 & 2 & 1 & 2 & 3 & 2 \\
\hline $\begin{array}{l}\text { Knowing which documents } \\
\text { are used and how much }\end{array}$ & 4 & 4 & 3 & 1 & 4 & 4 & 3 & 1,25 \\
\hline $\begin{array}{l}\text { Knowing how } \\
\text { online tools } h\end{array}$ & 3 & 3 & 4 & 1,25 & 4 & 4 & 4 & 1 \\
\hline $\begin{array}{l}\text { Finding the students who } \\
\text { are not doing well }\end{array}$ & 4 & 4 & 4 & 1 & 3 & 3,5 & 4 & 1 \\
\hline Finding the best students & 4 & 3 & 4 & 2 & 4 & 3 & 4 & 2 \\
\hline $\begin{array}{l}\text { Knowing how much time } \\
\text { students spent }\end{array}$ & 4 & 3 & 4 & 2 & 5 & 5 & 3 & 1 \\
\hline $\begin{array}{l}\text { Knowing if external learning } \\
\text { resources are used }\end{array}$ & 4 & 4 & 4 & 2 & 3 & 3 & 4 & 0 \\
\hline
\end{tabular}

(a) The CGIAR case study

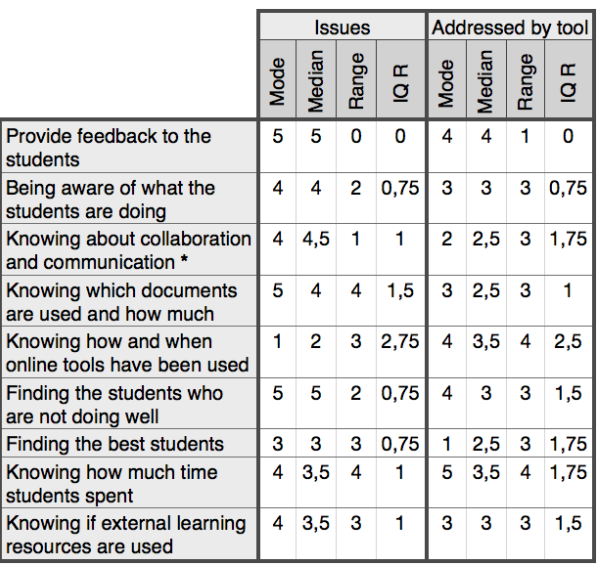

(b) The LAK case study

Table 1: Table of the Likert scale analysis of the teaching issues and the issues addressed by the tool (IQR=InterQuartile Range).

Due to low availability and bad Internet connection in third world countries, only three teachers responded. To increase participation, we contacted computer science (CS) and law professors and teaching assistants (TA). These teachers were not involved in the visualized courses, but as teachers they could still provide valuable feedback. In total, 20 persons participated: 3 agricultural, 2 law, 8 CS teachers and 7 CS TA's, of which 6 females and 14 males, between 24 to 66 years old. Nine teach less than 5 years.

The online survey inquired about the usefulness through a detailed study with Likert items, eight open free-text questions and multiple yes/no-questions on usage intentions. Although many usability surveys are available, we designed our own survey to enable a qualitative study on how teachers use SAM and it assists them.

Evaluation Results With Google Analytics ${ }^{5}$ the use of SAM was tracked. The 20 users visited SAM 48 times, spending 40 minutes on average. When removing two outliers, who probably kept their browser open, the average time spent is 29.5 minutes. First, the respondents rated 95 -scale Likert items about teaching issues (' 1 - not relevant' to ' 5 - very important'). Afterwards, we asked to rate whether the same issues could be addressed by the tool (' 1 - impossible' to ' 5 - definitely'). This way the real needs of the teachers can relate back to how they perceive SAM addresses these problems.

Table 1a shows the Likert scales on teaching needs and the needs SAM addresses according to the teachers. The most important issue for teachers is to provide feedback. They also grade 'being aware of what students do' and 'knowing which documents are used and how much' as important, followed closely by 'finding students who are not doing well'. The questions on resource use are rated equally important to finding students

\footnotetext{
${ }^{5}$ Google Analytics, http://analytics.google.com
} 


\begin{tabular}{|l|c|c|c|c|c|c|c|c|}
\cline { 2 - 10 } \multicolumn{1}{c|}{} & \multicolumn{4}{c|}{ CGIAR } & \multicolumn{4}{c|}{ LAK } \\
\cline { 2 - 10 } \multicolumn{1}{c|}{} & Mode & Median & Range & IQ R & Mode & Median & Range & IQ R \\
\hline Line Chart & 4 & 4 & 3 & 0,25 & 3 & 3,5 & 3 & 1 \\
\hline Parallel Coordinates & 4 & 4 & 4 & 1 & 3 & 3 & 3 & 1 \\
\hline Bar Chart & 4 & 4 & 3 & 1 & 3 & 3 & 4 & 1,25 \\
\hline
\end{tabular}

Table 2: Table of the Likert scale analysis of usefulness of the visualizations of the CGIAR and LAK case study (IQR=InterQuartile Range).

in trouble. 'Finding the best students' and 'Knowing how much time is spent' is less important, but still above average. The usage of online tools is only rated as moderately interesting. 'Knowing about collaboration and communication' (the $3^{\text {rd }}$ row with *) is something that we think cannot be solved by SAM, but is added to check a possible bias. The difference in responses from teachers and TA's has been statistically tested with Mann-Whitney's U tests. This uncovered that giving feedback is more important for teachers than for TA's (mean ranks of teachers $=12.19$ and TA's $=7.36 ; \mathrm{U}=23.5$, $\mathrm{Z}=-2.16, \mathrm{p}=0.02, \mathrm{r}=0.48)$. TA's find collaboration significantly less important than teachers (mean ranks of teachers $=12.73$ and TA's $=6.36 ; \mathrm{U}=16.5, \mathrm{Z}=-2.40, \mathrm{p}=0.01$, $r=0.54$ ). The results show that the awareness goal (see Section 3.1) (through 'provide feedback to students' and 'being aware of what students are doing') and resource use (through 'knowing which documents are used' and 'knowing if external resources are used') are rated as important. Time tracking is less important, but still above average.

From the addressed issues in Table 1a, the collaboration issue (the $3^{\text {rd }}$ row with *), used to check a bias, is rated the lowest as expected. However, the participants did not fully agree (high range and IQR). The highest rated was 'knowing how much time students spent', which is easily derived from the statistics window. 'Awareness of what students are doing' was also rated as high. 'Providing feedback to the students' scores a bit lower (mode $=4$, median $=3$, high range $\& I Q R$ ), potentially because it often requires more performance details, such as grades. For resource use, 'knowing which documents are used and how much' is rated quite high, as well as for the online tools, although the range is high. The external resource usage is indecisive. Finding students in trouble and the best students was also rated rather low. Some participants argued that time spending and resource usage is insufficient and that in most cases quantitative data does not demonstrate that students learned. Currently SAM provides only basic insights and can be improved by richer data, if available (e.g. grades), and additional visualizations. Comparing the results to the teacher goals, SAM handles the time tracking goal. The highly rated awareness goal has been partially met through 'Awareness of what students are doing', but can be improved. The resource use goal has been mostly met, but can be improved by differentiating external resources.

Table 2 assesses the usefulness of each visualization using 5-scale Likert items (' 1 - not useful at all' to ' 5 - very useful'). The line chart scores highest, than the bar chart and than the parallel coordinates. Two participants rated parallel coordinates as useless.

We also inquired why participants would use the different charts with open questions. They indicated that the time spending patterns are important to control the workload evolution during the course and to see when students really start working. Six 
persons use it to detect outliers for assistance. Three teachers look for dropouts and three use the line chart to learn about the behavior and progress. Most of the use of the line chart is related to the awareness, finding students in trouble and time tracking issue. The parallel coordinates are used by eight users to obtain a quick course overview and to compare students with more parameters than time only. Four persons like to compare students with the average student. Teachers also mentioned that it could be used for finding outliers, finding patterns and gaining a clearer overview on the student distributions per metric. The parallel coordinates are apparently more used to get a course overview and some teachers can detect students who need assistance. The bar chart is used by eight persons to check the student distribution and get a course overview. Six users use the bar chart to find outliers. Some teachers indicate uncertainty whether the outliers are really doing well or experiencing problems. The bar chart is also used for a course overview and awareness, but also for resource use. Only 5 teachers found the current resource recommendations useful. Teachers want to understand the resource use and are not interested in recommendations as such. The tag cloud was not always clear and some would prefer a list combined with statistics. Two stated that the recommendations might be more useful for students and 14 want to give SAM to their students.

The participants also proposed new features to improve SAM in another open question. Drilling down in the data (e.g. to obtain a list of students or documents in a bin in the bar chart) and to have more search capabilities (e.g. find a specific student) would be welcome. They also requested a wider range of metrics (e.g. the number of times a student works on the course was proposed) in the bar chart and parallel coordinates. The latter would also benefit from configurable axes (which we implemented for the LAK case study, see Section 4.2). Teachers want to access the details of every student.

When asked what insights they gained from SAM, three said that time spent was a good indicator for effort. Three understood the course workload and usage better, and two would like to use SAM for course design optimization. Three teachers understood the student distributions and found outliers. Eight participants would want to use it to increase awareness and obtain a course overview. Four would use it for statistical analysis and two for a course evaluation. 18 out of 20 would like to use it in their own courses and three requested to obtain the tool. From the teachers' eagerness to use SAM in their own courses, we can conclude that they perceive the added value for them.

\subsection{The Learning and Knowledge Analytics Case Study}

We also applied SAM in a large online open course on learning analytics. This way an audience active in the learning analytics domain can give feedback on SAM.

Evaluation Setup and Demographics The Learning and Knowledge Analytics (LAK) online course was organized in collaboration with the International Conference on Learning Analytics and Knowledge [1]. Moodle was used extensively for communication and collaborations via forums. We visualized the user activities of the Moodle system in SAM. 270 participants registered for the course. The participants are researchers 
active in the learning analytics field and/or teachers interested in learning analytics. Evaluating SAM in this diverse test bed triggered interesting discussions ${ }^{6}$.

We again used an online survey but with two paths: one for all users and one for teachers. The path for teachers is identical to the CGIAR case study to allow comparison. Some additional questions were added. In this case study we wanted to get more details on the use of SAM in a large course and the perceived usefulness of SAM by learning analytics experts. Twelve people, between 27 and 62 years old, completed our survey. Six of them are teaching courses and five for more than 10 years.

Evaluation Results We first discuss the results of the teachers. Six teachers rated the relevancy of the same 9 teaching issues as in the CGIAR case study in Section 4.1. Table $1 \mathrm{~b}$ shows that LAK teachers perceive teaching issues slightly different than the CGIAR teachers. The most important issue is again 'providing feedback to students'. The LAK teachers are very interested in finding students who are not doing well. Finding the best students is less important than in the CGIAR case. Both LAK and CGIAR teachers want to understand the document use. 'Knowing how and when online tools have been used' and 'knowing if external resources are used' is rated a bit lower. So they are probably more interested in the document use within Moodle. 'Student awareness' is also rated high. Collaboration and communication is more important for LAK teachers. The time tracking issue is almost rated the same. Comparing with the teacher goals (see Section 3.1), we see that awareness and resource is again the most important.

Table $1 \mathrm{~b}$ depicts that LAK teachers are more convinced that SAM addresses the 'providing feedback to students' issue. This might be related to their expertise in visual analytics. The time spending issue is scoring the second best, but this is less convincing as in the CGIAR case. On most other issues the teachers are indecisive (most medians about 3). The second part of the survey was targeted at both teachers and learners. When asked to assess the contribution of each visualizations, indecisive answers came out as well (all mode \& median around 3), see Table 2. There is no statistical evidence that teachers and learners would rate the visualizations differently.

The open questions on how to apply each of the visualizations gave better insights on the use of SAM. One teacher would use the line chart to detect the participation intensity and tendency. Another teacher can learn about 'chronological course dwell time'. The line chart can also be used to verify the classroom activity status. The teacher would expect it to be normal if few students participate much and few participate very little, while most are in the center. A student uses it for comparison with his peers. Three students use the parallel coordinates for comparison with the rest of the class for self-reflection, to measure progress and to increase motivation. One person did not understand how the parallel coordinates worked. He liked the bar chart to find the group where he fits in. The bar chart was perceived as a bit redundant by one teacher, maybe due to the addition of the histograms on the parallel coordinates.

Seven out of nine users find the recommendations useful. Eight want to continue using SAM and four are unsure. In an open question on what they liked about SAM, three mentioned its simplicity and the multitude they can observe. Two enjoyed the tool's speed. Two participants liked the accurate, detailed time information and the insight

\footnotetext{
${ }^{6}$ http: //scope.bccampus. ca/mod/forum/discuss.php?d=16525
} 
and motivation it provides. Although results of Table $1 \mathrm{~b}$ and 2 are hard to interpret, we can derive from the open questions and willingness to continue using SAM that most LAK users, perceive it as useful for different tasks. The study was affected by the incomplete user activity data of some users, who studied outside of the Moodle system.

Two learning analytics experts requested more details on forum use (e.g. comments in a time period), maybe due to the course's extensive forum use. Next, we asked them to prioritize visualization ideas from the CGIAR case study. From most desired to least, these are the results: (1) visualization on content creation by students, (2) used resource types visualization, (3) detailed statistics of used resources, (4) comparison of the actions of two students and (5) detailed student information. Some ideas can be embedded in the parallel coordinates, e.g. metrics on content creation and resource types.

\section{Conclusion and future work}

We presented SAM, a visualization tool to provide an overview of activities in a virtual classroom and to enable both students and teachers to explore user activities and find patterns, contributing to awareness and self-monitoring. We evaluated the effectiveness of SAM to assess what works well in two real-world settings. The CGIAR case study shows that SAM contributes to creating awareness for teachers, as evidenced by the survey results. SAM meets the time tracking goal. The resource use can be improved by differentiating internal and online resources. Overall, teachers would like more statistics. Currently, we focus on resource access and time spent [8], but other metrics can be easily added. In both case studies, test subjects reported various strategies to become aware of student activities, e.g. the parallel coordinates are used to get an overview and the line chart is used to detect outliers. SAM's three visualizations were perceived as useful in the CGIAR case and 18 out of 20 teachers would like to use SAM in their own courses. This confirms that SAM provides useful functionality for teachers.

The results from the Likert scales in the LAK case study are indecisive. From the open questions, we learned that the LAK participants employed SAM to come to similar conclusions, e.g. find outliers. Generally, they also perceived SAM as useful for various tasks. Missing data for learners who spent most of their time offline also affected the results. The learning analytics experts provided new ideas, e.g. statistics on content creation. The users of the CGIAR case also proposed new features related to finding students and drilling down in the data. They also requested additional metrics to improve awareness, which can be easily added to the parallel coordinates and bar chart.

After extending SAM, we want to re-evaluate it with teachers. A large evaluation with students allowing the effects of SAM over time is also planned in an engineering course. Several institutes requested to use SAM in the LAK course. Tallinn University ${ }^{7}$ would like to use SAM to visualize all their Moodle courses for teachers. In this way, we are confident that we will be able to carry out larger scale evaluations in the future.

Acknowledgements. This research is funded by the European Commission's Seventh Framework Programme (FP7/2007-2013) under grant agreement no 231396 (ROLE). Katrien Verbert is a Postdoctoral Fellow of the Research Foundation - Flanders (FWO).

\footnotetext{
7 Tallinn University, http: / / www . t lu . ee/
} 


\section{References}

1. 1st International Conference on Learning Analytics and Knowledge 2011 (February 2011), https://tekri.athabascau.ca/analytics/

2. Allendoerfer, K.R.: How information visualization systems change users' understandings of complex data. Ph.D. thesis, Drexel University (2010)

3. Blakelock, J., Smith, T.E.: Distance learning: From multiple snapshots, a composite portrait. Computers and Composition 23(1), 139-161 (2006)

4. Dawson, S., Bakharia, A., Heathcote, E.: Snapp: Realising the affordances of real-time SNA within networked learning environments. In: Proceedings of the 7th International Conference on Networked Learning 2010. pp. 125-133 (2010)

5. Govaerts, S., Verbert, K., Klerkx, J., Duval, E.: Visualizing activities for self-reflection and awareness. In: Luo, X., Spaniol, M., Wang, L., Li, Q., Nejdl, W., Zhang, W. (eds.) ICWL. Lecture Notes in Computer Science, vol. 6483, pp. 91-100. Springer (2010)

6. van Harmelen, M.: Personal learning environments. In: ICALT '06: Proc. of the 6th IEEE Int. Conf. on Advanced Learning Technologies. pp. 815-816. IEEE Computer Society (2006)

7. Janssen, J., Erkens, G., Kanselaar, G., Jaspers, J.G.M.: Visualization of participation: Does it contribute to successful computer-supported collaborative learning? Computers \& Education 49(4), 1037-1065 (2007)

8. Keith, T.Z.: Time spent on homework and high school grades: A large-sample path analysis. Journal of Educational Psychology 74(2), 248-253 (April 1982)

9. Kelly, A.: Design research in education: Yes, but is it methodological? Journal of the Learning Sciences 13(1), 115-128 (2004)

10. Larusson, J.A., Alterman, R.: Visualizing student activity in a wiki-mediated co-blogging exercise. In: CHI '09: Proceedings of 27th International Conference on Human Factors in Computing Systems. pp. 4093-4098. ACM (2009)

11. Rath, A.S., Devaurs, D., Lindstaedt, S.N.: UICO: an ontology-based user interaction context model for automatic task detection on the computer desktop. In: Proc. of the 1st Workshop on Context, Information and Ontologies. pp. 8:1-8:10. CIAO '09, ACM (2009)

12. Schmitz, H.C., Scheffel, M., Friedrich, M., Jahn, M., Niemann, K., Wolpers, M.: Camera for PLE. In: Cress, U., Dimitrova, V., Specht, M. (eds.) EC-TEL. Lecture Notes in Computer Science, vol. 5794, pp. 507-520. Springer (2009)

13. Siirtola, H., Laivo, T., Heimonen, T., Raiha, K.J.: Visual perception of parallel coordinate visualizations. In: IV '09: Proc. of 13th Int. Conf. of Info. Visual. pp. 3-9. IEEE (2009)

14. Sinclair, J., Cardew-Hall, M.: The folksonomy tag cloud: when is it useful? Journal of Information Science 34, 15-29 (February 2008)

15. Soller, A., Martínez-Monés, A., Jermann, P., Muehlenbrock, M.: From mirroring to guiding: A review of state of the art technology for supporting collaborative learning. I. J. Artificial Intelligence in Education 15(4), 261-290 (2005)

16. Thomas, J.J., Cook, K.A.: Illuminating the Path: The Research and Development Agenda for Visual Analytics. National Visualization and Analytics Ctr (2005)

17. Wolpers, M., Martin, G., Najjar, J., Duval, E.: Attention metadata in knowledge and learning management. In: Proceedings of I-Know 2006: 6th International Conference on Knowledge Management. pp. 1-8 (2006)

18. Zhang, H., Almeroth, K., Knight, A., Bulger, M., Mayer, R.: Moodog: Tracking students' online learning activities. In: Proc. of World Conf. on Educational Multimedia, Hypermedia and Telecomm. 2007. pp. 4415-4422. AACE, Vancouver, Canada (2007)

19. Zimmerman, B.J.: Becoming a self-regulated learner: An overview. Theory Into Practice 41(2), 65-70 (2002) 